\title{
Spontaneous Fundal Uterine Rupture in a Pregnant Woman at 32 Weeks Gestation Who had Two Previous Cesarean Sections
}

\author{
Metin KABA ${ }^{1}$, Aysegül ÖKSÜZOĞLU ${ }^{1}$, Hakan TİMUR¹, Eren AKBABA¹, Gökçen KABA², Yaprak ENGIN ÜSTÜN1 \\ Ankara, Turkey
}

\begin{abstract}
Spontaneous uterine rupture during pregnancy can cause severe complications, even maternal and fetal demise. We report successful management of a spontaneous fundal uterine rupture in a 32 week pregnant who had undergone two previous cesarean sections due to preterm delivery. We explain causes of spontaneous uterine rupture and the management of this rare event in the presented case report.
\end{abstract}

Keywords: Spontaneous uterine rupture, Incision scar, Maternal morbidity, Fetal morbidity

Gynecol Obstet Reprod Med 2017;23(2):105-107

\section{Introduction}

Spontaneous uterine rupture (SUR) is defined as disruption or tear of the myometrium and serosa of the uterus that could lead to premature fetal delivery and its related complications, neonatal neurological impairment, maternal genito-urinary tract injury, hemorrhage, shock, and even both maternal and fetal death $(1,2)$. SUR is an emergency condition that requires prompt diagnosis and intervention to prevent maternal and fetal morbidity (3). Although SUR usually occurs with a scarred uterus, it may occur in an unscarred pregnant uterus at a rate of $1 / 5.700$ to $1 / 20.000$ pregnancies (4).

We present herein a case of SUR at 32 weeks gestation in a patient who had undergone two previous cesarean sections due to preterm delivery. To our knowledge, this is the first case of uterine fundal rupture in a patient who had undergone two previous cesarean sections.

${ }^{I}$ Department of Obstetrics and Gynecology, Zekai Tahir Burak Women's Health Education and Research Hospital, Ankara

${ }^{2}$ Department of Internal Medicine Ankara Education and Research Hospital, Ankara

Address of Correspondence: Metin Kaba

Department of Obstetrics and Gynecology Zekai Tahir Burak Women's Health Education and Research

Hospital Ankara, Turkey

metinkaba12@hotmail.com

Submitted for Publication: $\quad$ 15. 09. 2015

Accepted for Publication:

06. 01.2016

\begin{tabular}{|c|c|}
\hline & Access this article online \\
\hline $\begin{array}{c}\text { Quick Response Code: } \\
\text { and }\end{array}$ & Website: www.gorm.com.tr \\
\cline { 2 - 3 } & DOI:10.201613/GORM.2016.488 \\
\hline
\end{tabular}

How to cite this article: Kaba M. Öksüzoğlu A. Timur H. Akbaba E. Kaba G. Engin Üstün Y. Spontaneous Fundal Uterine Rupture in a Pregnant Woman at 32 Weeks Gestation Who had Two Previous Cesarean Sections. Gynecol Obstet Reprod Med 2017;23(2):105-7

\section{Case Report}

A 33 year-old woman, gravida 3, para 2, alive 0, was admitted with lower abdominal pain and tenderness at 30 weeks gestation. There was $3 \mathrm{~cm}$ cervical dilatation, and 60\% effacement at vaginal examination. She had two low transverse cesarean sections with a diagnosis of preterm birth in 1997 and 2010. The first fetus was delivered at 32 weeks and the second one at 26 weeks gestation. Unfortunately, the two fetuses died due to prematurity. She had been using enoxaparin $0.4 \mathrm{ml}$ daily and propiltiouracil $50 \mathrm{mg}$ daily with a diagnosis of thrombophilia and hyperthyroidism, respectively. Her family history was uneventful.

There was a viable fetus compatible with 30 weeks gestation, placenta localized at the anterior uterine wall, amniotic fluid index was normal, and cervical length was $9 \mathrm{~mm}$ in the obstetric ultrasonography evaluation. There was uterine contraction at tocography. The patient was admitted to the highrisk pregnancy clinic with a diagnosis of a threat of premature birth. Her vital signs and laboratory tests were normal. She was given tocolytic therapy, which included intravenous hydration and sedation with intravenous diazepam. Two doses of betamethasone $(12 \mathrm{mg}$ ) were injected intramuscularly. Following initial therapy, the uterine contractions ceased. The pregnant woman was observed in the clinic.

During observation she described acute pain in her lower abdomen at 32 weeks gestation. There was tenderness in the entire abdomen, the uterus was contracted, and there was no vaginal bleeding. The fetal heart beat could not be detected with a cardiograph. An emergency ultrasonographic evaluation showed that the fetus was in the uterine cavity and the fetal heart beat was very bradycardic. An immediate laparotomy was performed with provisional diagnosis of placental abruption or uterine scar rupture. There was a uterine rupture with a length of approximately $10 \mathrm{~cm}$. Whole layers of the uterine wall were separated. An $1890 \mathrm{~g}$ female infant was de- 
livered through the rupture area. The Apgar scores at 1 and 5 minutes were 6 and 8 , respectively. The fetus was admitted to the newborn intensive care unit due to prematurity. Approximately $80 \%$ of the placenta abruption was noticed and the retained placenta was extracted with manual intervention. Then we recognized that the rupture was at the uterine fundus instead of previous cesarean scar. The uterine rupture side was repaired with a continuous locking stitch with a 1-0 polyglactin suture with a double layer. The visceral peritoneum was dissected from over the vesico-uterine pouch to control the previous cesarean scar and it was noticed that the previous incision scar was intact (Figure 1). Approximately $1000 \mathrm{~mL}$ of blood was aspirated from the abdomen. The patient's hemoglobin 6.9 level was $\mathrm{g} / \mathrm{dL}$ at the postoperative sixth hour evaluation. To improve hemoglobin level two units of red blood cell packs were transfused.

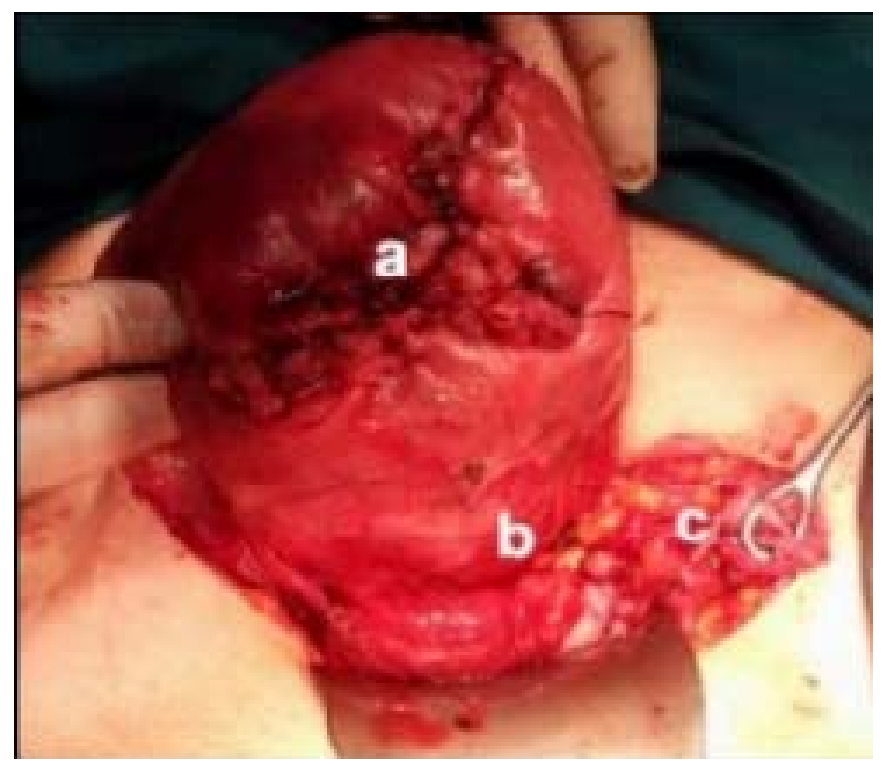

Figure 1: Sutured spontaneous uterine fundal rupture with double layer locking technique; resected bladder, and previous cesarean scar are shown. On the figure, the letter a: indicates the sutured spontaneous uterine fundal rupture side; the letter b: indicates the previous cesarean incision scar, and the letter $c$ : indicates the dissected bladder.

There was no fetal acidosis in the blood gas evaluation. The infant was treated with continuous positive airway pressure for four days. Surfactant therapy was given to the infant for treatment of neonatal respiratory distress syndrome. The woman and the infant were discharged from the hospital in good condition on the sixth postoperative day.

\section{Discussion}

Spontaneous uterine rupture in an unscarred uterus is a rare event and is one of the most serious preventable obstetrical emergencies. It has a high risk for maternal and fetal morbidity and mortality with an $80-95 \%$ perinatal mortality rate (5). Maternal and fetal morbidity and mortality are more common in patients with an unscarred uterus. Because of the lack of a defined weak area, such as a previous incision, the tear may progress and involve adjacent vital organs, leading to more serious complications (6). The risk factors for SUR at unscarred locations are grand multiparity, over - distension of the uterine cavity, obstructed labor, and induction with misoprostol, fetal malpresentation, placenta percreta, abruption placenta and adenomyosis (7). The pathogenesis of rupture of the unscarred uterus is not well-defined. Rupture in these cases has been attributed to inherent or acquired weakness of the myometrium, disorders of the collagen matrix (EhlersDanlos type IV) and abnormal architecture of the uterine cavity (bicornuate uteri, uterus didelphys), whereas some cases have no obvious cause $(3,8)$. Regarding our case, the rupture area was at the uterine fundus while the previous scar was intact. In this condition we were not able to identify the cause of the fundal SUR. Possible contributing factors for SUR in this case may have been preterm birth, placental abruption and multigravida.

The clinical signs and symptoms of uterine rupture are non-reassuring fetal heart rate pattern, variable heart rate decelerations that may evolve into late decelerations, bradycardia, fetal death, loss of engagement of the presenting fetal part, abdominal pain, vaginal bleeding, signs of intra-abdominal bleeding, hematuria, and maternal shock $(9,10)$. Fetal heart rate abnormality and maternal abdominal pain were observed in our case. Unfortunately, these symptoms and signs are typically non-specific for SUR. If the newborn infant is delivered within 17 minutes of the sudden onset of severe and prolonged deceleration of the fetal heart rate resulting from uterine rupture, perinatal morbidity is minimized (2).

After delivery of the fetus, the treatment options are repair of the ruptured area or performing a hysterectomy. The definitive surgery should be based on a combination of factors, including the patient's desire for future pregnancy, the extent of uterine damage from the rupture, the patient's intraoperative hemodynamic and anesthetic stability, and the skill of the surgeon (3). The optimal repair technique has not been established due to the rarity of uterine rupture, variability in location and extent of damage, and scarcity of long-term followup data. A reasonable approach is to repair the uterine defect in two or three layers with an absorbable suture. In our case the patient's vital signs and symptoms were stable during the operation. Therefore, we preferred a repair of the ruptured edge in a two-layer manner.

Women with a prior uterine rupture should be adequately counseled regarding maternal/fetal risks in subsequent pregnancies. The risk of recurrent rupture appears to be highest when the uterine fundus is involved (11). We informed the patient about the future risk of uterine rupture before discharge.

In conclusion, spontaneous uterine rupture is a rare event that is unpredictable and is associated with high rates of maternal and neonatal morbidity. Clinical suspicion, early diag- 
nosis and timely intervention can decrease maternal and fetal morbidity and mortality. Therefore, the physician should be aware of spontaneous uterine rupture and should know its risk factors, signs and symptoms. Due to the rarity of uterine rupture, more evidence should be reported to increase knowledge on this issue.

\section{References}

1. Kiseli M, Artas H, Armagan F, Dogan Z. Spontaneous rupture of uterus in midtrimester pregnancy due to increased uterine pressure with previous laparoscopic myomectomy. Int J Fertil Steril 2013;7(3):239-42.

2. Chauhan SP, Martin JN Jr, Henrichs CE, Morrison JC, Magann EF. Maternal and perinatal complications with uterine rupture in 142.075 patients who attempted vaginal birth after cesarean delivery: A review of the literature. Am J Obstet Gynecol 2003;189(2):408-17.

3. Tola EN. First trimester spontaneous uterine rupture in a young woman with uterine anomaly. Case Rep Obstet Gynecol 2014;2014:967386.

4. Zwart JJ, Richters JM, Ory F, de Vries JI, Bloemenkamp KW, van Roosmalen. Uterine rupture in The Netherlands: a nationwide population-based cohort study. BJOG 2009;116(8):1069-78

5. Singh A, Shrivastava C. Uterine Rupture: Still a Harsh
Reality! J Obstet Gynaecol India 2015;65(3):158-61.

6. Ofir K, Sheiner E, Levy A, Katz M, Mazor M. Uterine rupture: differences between a scarred and an unscarred uterus. Am J Obstet Gynecol 2004;191(2):425-29.

7. Shirata I, Fujiwaki R, Takubo K, Shibukawa T, Sawada K. Successful continuation of pregnancy after repair of a midgestational uterine rupture with the use of a fibrincoated collagen fleece (TachoComb) in a primigravid woman with no known risk factors. Am J Obstet Gynecol 2007;197(4):e7-9.

8. Pepin M, Schwarze U, Superti-Furga A, Byers PH. Clinical and genetic features of Ehlers-Danlos syndrome type IV, the vascular type. NEJM 2000;342(10):673-80.

9. Suwannarurk K, Pongrojpaw D, Manusook S, Suthiwartnarueput W, Bhamarapravatana K. Spontaneous uterine rupture at non-cesarean section scar site with placenta percreta in the second trimester: a case report. J Med Assoc Thai 2014;97(Suppl 8):208-12.

10. Kwee A, Bots ML, Visser GH, Bruinse HW. Uterine rupture and its complications in the Netherlands: a prospective study. Eur J Obstet Gynecol Reprod Biol 2006;128(12):257-61.

11. Usta IM, Hamdi MA, Musa AA, Nassar AH. Pregnancy outcome in patients with previous uterine rupture. Acta Obstet Gynecol Scand 2007;86(2):172-6. 